\title{
STRESS ANd Fatigue ANAlysis of a Single Cylinder Engine Crankshaft
}

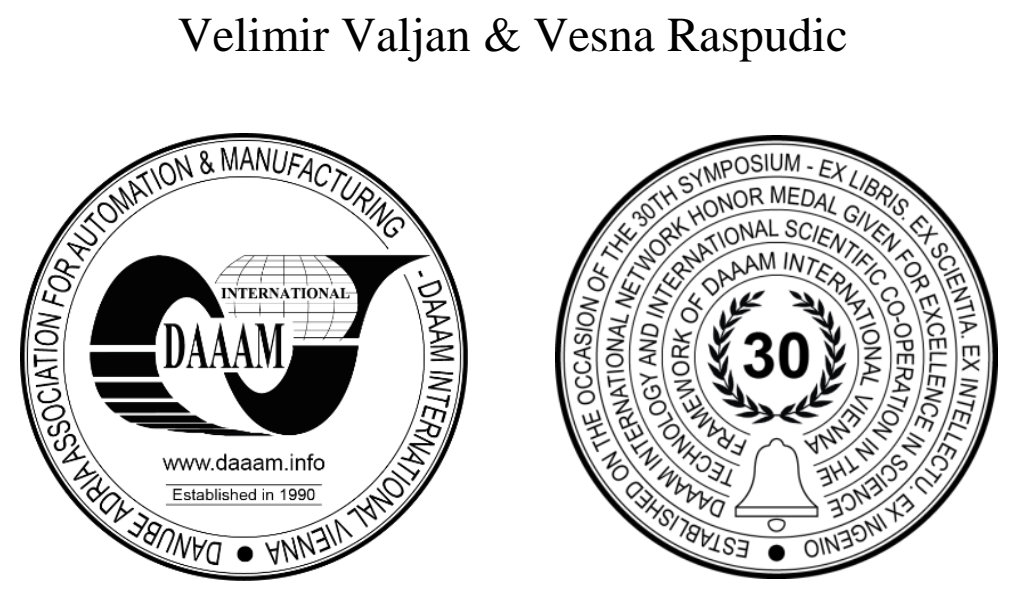

This Publication has to be referred as: Valjan, V[elimir] \& Raspudic, V[esna] (2020). Stress and Fatigue Analysis of a Single Cylinder Engine Crankshaft, Proceedings of the 31st DAAAM International Symposium, pp.0692-0700, B. Katalinic (Ed.), Published by DAAAM International, ISBN 978-3-902734-29-7, ISSN 1726-9679, Vienna, Austria DOI: $10.2507 / 31$ st.daaam.proceedings.096

\begin{abstract}
To perform a stress analysis of a crankshaft over the entire cycle of an IC engine, one has to possess a loading history, i.e. the magnitude of the load should be available for every position of the crankshaft during the cycle. This loading history has been obtained through a dynamic analysis done in MATLAB and used in the finite element based stress analysis performed in SolidWorks Simulation 2019. After finding the optimal mesh using the manual h-convergence method, the FE analysis yielded the results neccessary for the fatigue life predictions at previously chosen critical locations. Fatigue performance of the crankshaft was evaluated both analytically and numerically.
\end{abstract}

Keywords: dynamic analysis; MATLAB; FEA; SolidWorks; fatigue analysis

\section{Introduction}

The longevity and reliability of internal combustion engines depend heavily on the quality of the engine's crankshaft. The geometry of a crankshaft is very complex and depends, among others, on the type of the engine and the number of cylinders. The purpose of the crankshaft is to transfer the reciprocating translational movement of the piston into the smooth rotation which can be more easily used as a power source for other machines. Main parts of a crankshaft are the main journals, rod journals, crank webs and counterweights. Crankshaft of a single cylinder four stroke engine that has two main journals and one rod journal was chosen to be the subject of this study because analyses of such crankshafts require less computational resources than those of multi cylinder engine crankshafts. Also, the geometry of multi cylinder engine crankshafts is often reduced to just one crank throw (portion of geometry consisting of one rod journal and two crank webs) when conducting a finite element analysis (FEA). This type of crankshaft is frequently used in lawnmowers and various agricultural machines. Different materials, manufacturing processes, surface and heat treatments have significant influence on the performance of the crankshaft. There are two competing major manufacturing processes that use two different materials: forging (using forging steel) and casting (using ductile iron cast).

The main failure mechanism of crankshafts is fatigue, so special attention needs to be dedicated to fatigue-related characteristics of the crankshaft's material. In general, forged machine elements have more favourable homogeneous structure, resulting in longer fatigue life compared to castings, which are known to have properties, such as porosity, that facilitate crack initiation and crack growth [1]. 
Multiple different studies have proven that this is the case for crankshafts also, claiming that forged crankshafts have as much as 6 times longer life than crankshafts made of ductile iron cast [2], [3]. One of the goals of the surface and heat treatments is to induce residual compressive stresses in the areas of the crankshaft where cracks usually initiate - the filleted regions that connect the crank webs with the rod and main journals. Residual compressive stresses can prolong the initiation of cracks and consequently extend the life of the crankshaft [4]. Local plastic deformations caused by the processes of fine grinding and fillet rolling induce the desirable residual stresses, and these techniques are widely used in the production of various other machine elements [3], [5]. Uniform distribution of surface hardness is also recommended, since the decrease of hardness at a location usually implies a decrease in yield and ultimate strength, leading to a shorter fatigue life [5]. As the initial cracks propagate, the deformations of the crankshaft increase as its stiffness decreases, which can cause the loss of functionality even before the failure occurs [3]. Careless surface treatments can have catastrophic consequences on the crankshaft's fatigue life, as was presented in [6] and [7]. These studies have found out that the cause of a diesel van crankshaft failure was an improper grinding process, during which thermal fatigue cracks initiated at the crankshaft's journals, and later led to its failure. The causes of crankshaft failures were categorized as mechanical (e.g. vibrations of the crankshaft), operational (e.g. oil absence, defective lubrication) and repairing (e.g. improper welding, defective grinding).

The series of papers and reports as [2], [3], [8], [9] and [10] pose an invaluable source of information about the manufacturing processes, heat and surface treatments, dynamic, stress and fatigue analysis of crankshafts. Single cylinder crankshafts from two competing industries, casting and forging, were thoroughly compared, analytically, numerically and experimentally. The results from the dynamic, stress and fatigue analysis were used in the optimization process, which achieved an $18 \%$ weight reduction while also reducing the manufacturing costs and increasing the fatigue strength. The finite element method was used to perform a stress and modal analysis of a four cylinder diesel engine in [11], resulting in the determination of the maximum deformation, maximum stress and the critical locations, as well as the relation between frequency and the vibration modes. A very similar analysis has been presented in [12], but here only a portion of the crankshaft was investigated. The stress and fatigue analyses of a single cylinder engine crankshaft were followed with a geometry optimization, concentrated on the relation between the rod journal diameter and the fillet radius, in [13]. The optimization resulted in $25 \%$ stress reduction while also extending the fatigue life of the component. Failures of two crankshafts from two single cylinder diesel engines were investigated in [14]. A static FEA was carried out to find the stress variation at critical locations. An important takeaway from the literature review is that almost all papers found the critical location to be the fillet connecting the rod journal and the crank web [2], [5], [8], [10], [11], [12], [13], [14], [15]. This fact could later help in the validation of the results from the stress analysis.

This paper will present a dynamic, stress and fatigue analysis of a forged steel crankshaft. The dynamic analysis is done analytically and then automated in MATLAB. In this way, the magnitude and direction of load for any position of the crankshaft, at any arbitrary engine speed (rpm) can be easily found, and then applied in the finite element based stress analysis. Conducting the stress analysis for multiple crankshaft positions is necessary in order to get the stress history at critical locations. From this stress history, the mean and alternating stresses will be derived and used in the fatigue analysis, which will be done both analytically and numerically.

\section{Dynamic Analysis}

The crankshaft is subjected to a complex combination of different loads during the engine cycle. Dynamic analysis will take into consideration the influence of inertial $F_{\text {in }}$ and combustion loads $F_{\text {com }}$ only. Magnitude of the friction forces is neglectful compared to the combustion and inertial loads so they will be omitted here, nevertheless, friction forces should be included in the analysis when designing the parts of the engine's slider-crank mechanism. Inertial loads caused by the translational and rotational movement of the piston assembly and the connecting rod are determined for the global coordinate system shown in Fig. 1., located in the center of rotation of the crankshaft, with the $\mathrm{x}$ axis oriented towards the cylinder, collinear with its axis, and the $\mathrm{y}$ axis perpendicular to the $\mathrm{x}$ axis.

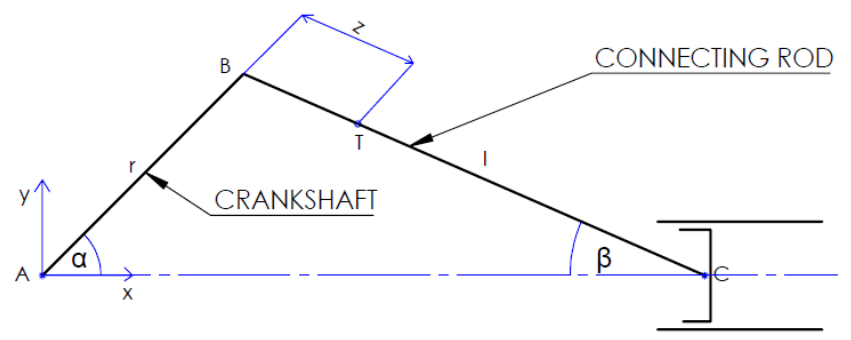

Fig. 1. Global coordinate system

These loads can be balanced and unbalanced. Balanced loads affect only the parts in the engine's slider-crank mechanism, while the unbalanced forces also produce vibrations that affect the whole engine. The first step in the dynamic analysis is to find the position of the center of mass of the piston and the connecting rod, dependent on the current position of the crankshaft (defined by the angle $\alpha$, starting at $0^{\circ}$ at the beginning of the intake stroke), in the global coordinate system. 
By differentiating these expressions, the linear velocity and acceleration of the piston and the connecting rod in the $\mathrm{x}$ and y directions can be determined throughout the whole engine cycle, as well as the inertial loads caused by their movement. The combustion loads acting on the upper surface of the piston can be defined with (1), where $p(\alpha)$ is the pressure in the cylinder, and A is the area of the piston's surface:

$$
\mathrm{F}_{\mathrm{com}}=\mathrm{p}(\alpha) * \mathrm{~A}
$$

Obviously, to calculate the magnitude of the combustion load at every position of the crankshaft, the $\mathrm{p}$-V diagram of the particular engine has to be available. For different engine speeds the diagram changes, but the maximum pressure remains constant, so the same diagram can be used for analyses at various speeds [8]. The p-V diagram can easily be transformed into the $p-\alpha$ diagram. The $p$ - $\alpha$ diagram for the chosen engine was taken from [2] and then imported in the WebPlotDigitizer software [16], which was used to extract the value of the cylinder pressure at 277 different crankshaft angles. These values were saved in a CSV file, and later imported in the MATLAB program as two matrices with the csvread command. The program used the value of the pressure at a given angle and the piston diameter to calculate the combustion load at that moment. For the calculation of the inertial loads, the program needed only the dimensions of the parts of the slider-crank mechanism. A detailed description of the dynamic analysis process is described in [2]. Only the final expressions for loads acting on the rod journal in $\mathrm{x}$ and $\mathrm{y}$ direction are provided here:

$$
\begin{aligned}
& \mathrm{F}_{\mathrm{X}}=\mathrm{p}(\alpha) * \mathrm{~A}+\mathrm{m}_{\text {pis }} \mathrm{a}_{\text {pis }}+\mathrm{m}_{\text {rod }} \mathrm{a}_{\mathrm{x}_{\text {_rod }}} \\
& \mathrm{F}_{\mathrm{y}}=\frac{1}{\mathrm{l}}\left(\frac{\mathrm{I}_{\mathrm{zz}} \varepsilon_{\text {rod }}-\left(\mathrm{p}(\alpha) * \mathrm{~A}+\mathrm{m}_{\text {pis }} \mathrm{a}_{\text {pis }}\right)(\mathrm{l}-\mathrm{z}) \lambda \sin \alpha}{\sqrt{1-\lambda^{2} \sin ^{2} \alpha}}+\mathrm{m}_{\text {rod }} \mathrm{a}_{\mathrm{y}_{-} \text {rod }}(\mathrm{l}-\mathrm{z})\right)
\end{aligned}
$$

a and $\varepsilon$ represent the linear and angular accelerations, and $\lambda$ is the ratio of the crankshaft radius $r$ and the connecting rod length 1 . The dimensions of the slider-crank mechanism parts are listed in the table 1, taken from [8]:

\begin{tabular}{|c|c|}
\hline Connecting rod length l & $120.78 \mathrm{~mm}$ \\
\hline Mass of the connecting rod $\mathrm{m}_{\text {rod }}$ & $0.283 \mathrm{~kg}$ \\
\hline Area of the upper surface of the piston & $6217.985 \mathrm{~mm}^{2}$ \\
\hline Mass of the piston assembly $\mathrm{m}_{\text {pis }}$ & $0.417 \mathrm{~kg}$ \\
\hline $\mathrm{I}_{\mathrm{zz}}$ of the connecting rod about the center of gravity & $0.663 \times 10^{-3} \mathrm{~kg} \times \mathrm{mm}^{2}$ \\
\hline Distance of the connecting rod's center of gravity $\mathrm{z}$ & $28.6 \mathrm{~mm}$ \\
\hline Crankshaft radius $\mathrm{r}$ & $32.512 \mathrm{~mm}$ \\
\hline
\end{tabular}

Table 1. Dimensions of the parts of the slider-crank mechanism
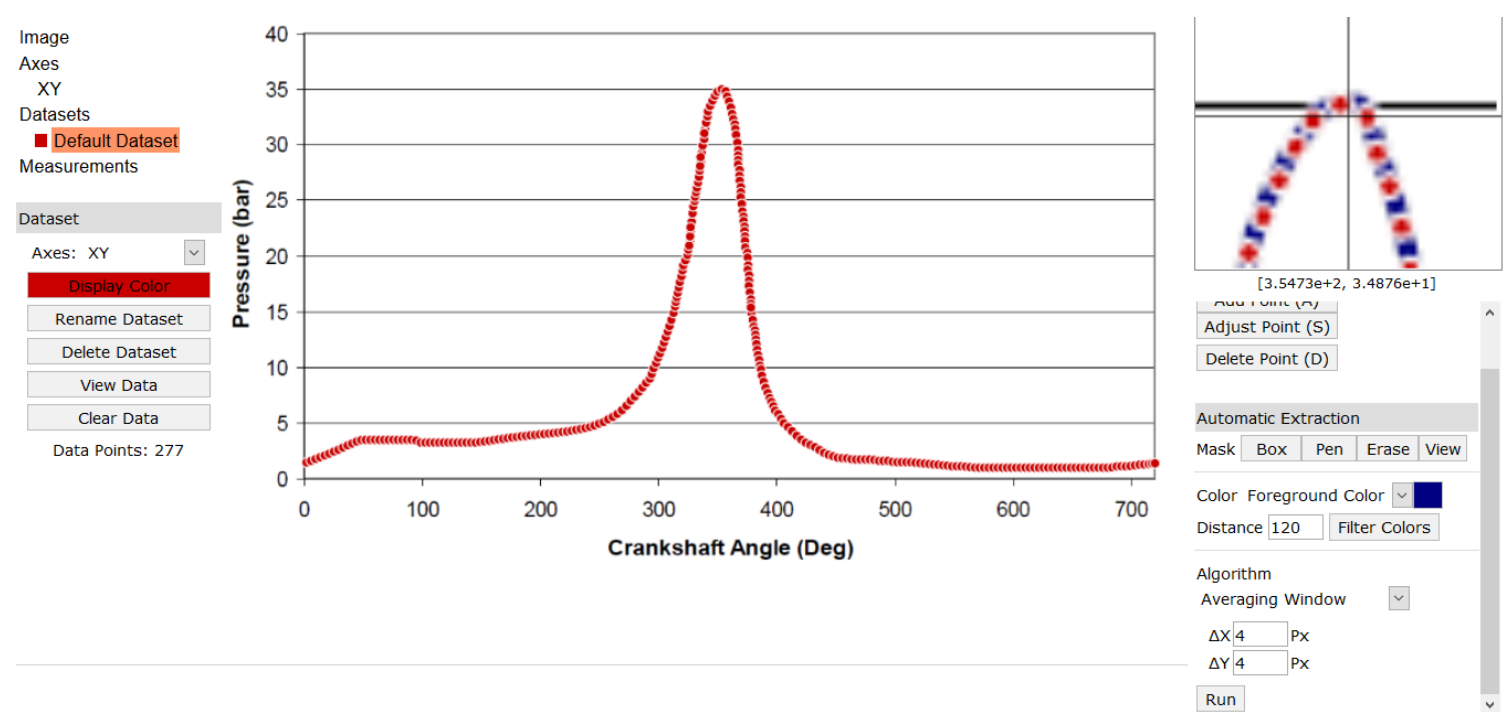

Fig. 2. Extracting the pressure values with the WebPlotDigitizer software

The forces acting on the crankshaft's rod journal are usually expressed in the local coordinate system positioned in the rod journal, which rotates with the crankshaft. The radial (bending) component of the force is acting perpendicular to the crankshaft's longitudinal axis, and the tangential (torsional) component is acting in the direction of the rotation, perpendicular to the radial component. Expressing the forces in this coordinate system will make it a lot easier to define the boundary conditions in the FEA. The total load can be defined in any of the two used coordinate systems. 


$$
\begin{aligned}
& \mathrm{F}_{\mathrm{T}}=-\mathrm{F}_{\mathrm{x}} \sin \alpha+\mathrm{F}_{\mathrm{y}} \cos \alpha \\
& \mathrm{F}_{\mathrm{R}}=\mathrm{F}_{\mathrm{x}} \cos \alpha+\mathrm{F}_{\mathrm{y}} \sin \alpha \\
& \mathrm{F}_{\mathrm{TOT}}=\sqrt{\mathrm{F}_{\mathrm{x}}^{2}+\mathrm{F}_{\mathrm{y}}^{2}}=\sqrt{\mathrm{F}_{\mathrm{R}}^{2}+\mathrm{F}_{\mathrm{T}}^{2}}
\end{aligned}
$$

The dynamic analysis is performed for constant engine speeds only, since neglecting the angular acceleration of the crankshaft simplifies the process, without significantly affecting the final results [2]. The MATLAB program computes all of the above explained load components and also gives their graphical representation.

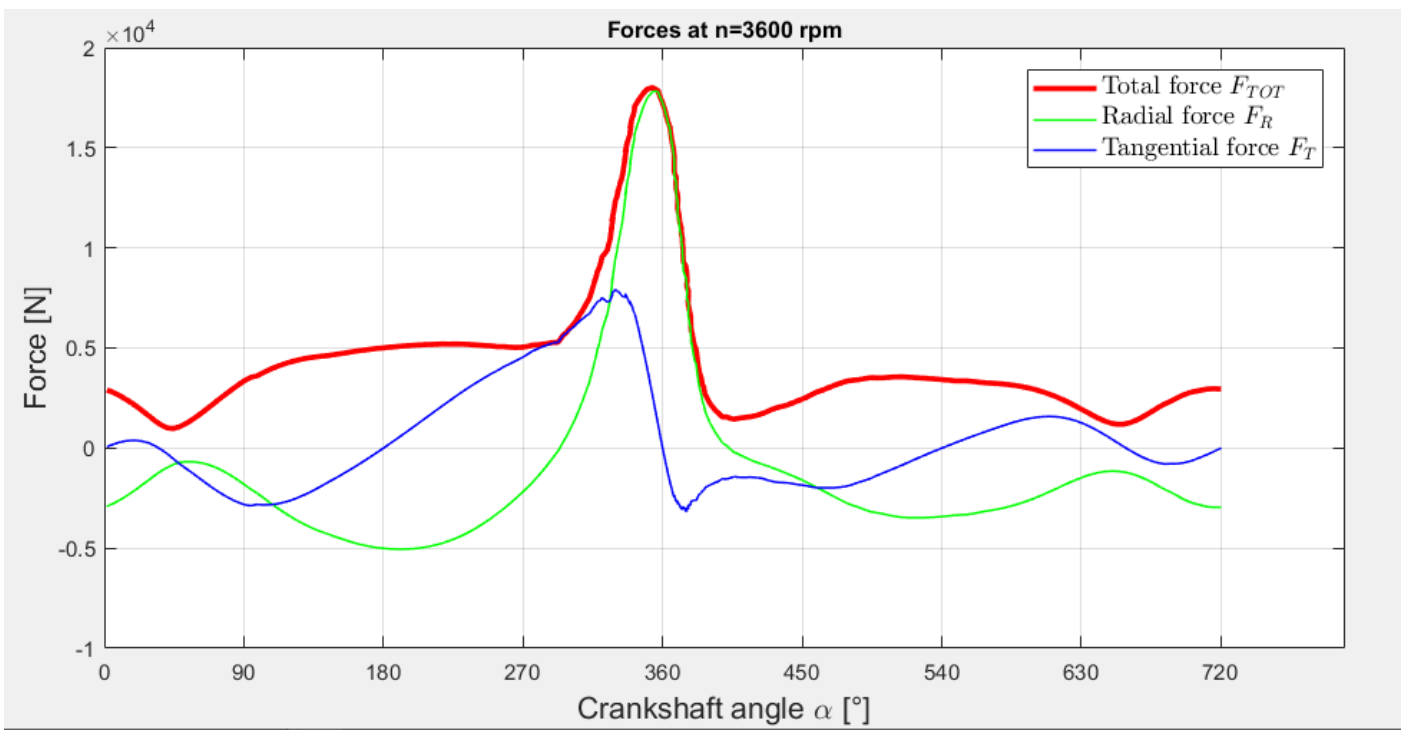

Fig. 3. Forces acting on the rod journal at $3600 \mathrm{rpm}$

As Fig. 3. shows, the maximum magnitude of the total force occurs roughly at $360^{\circ}$, i.e. at the end of the compression stroke, which corresponds to the maximum of the combustion load also. The inertial load acts in the opposite direction at this moment, which is why the magnitude of the total force will decrease if the speed increases, since the inertial force would increase too [8]. On the other hand, the crankshaft is more prone to wear and lubrication problems at higher speeds [9].

\section{Stress Analysis}

Performing an analytical stress analysis isn't practical because of the complexity of the crankshaft's geometry [3], [17], therefore the numerical approach using the finite element method will be utilized. The FEA is an approximate numerical method for solving problems in every engineering branch. Based on assumptions and simplifications derived from the physical principles and real boundary conditions, a certain physical problem is deducted to a mathematical model which consists of a governing differential equation [18], [19]. The FEM transforms the differential equation into a system of algebraic equations which is easier to solve with the help of modern computers. Machine elements analysed with the FEM can have arbitrary shapes, can be made of multiple different materials, be anisotropic or nonhomogeneous, which presents an enormous advantage over the traditional analytical methods. In this work, the modelling and stress analysis of the crankshaft was conducted in the SolidWorks 2019 software. Second order solid tetrahedral elements were used in the discretization process. This type of finite elements was also used in many other investigated studies [2], [3], [8], [13]. The material used in the analysis is DIN 1.0503 steel, whose properties from SolidWorks 2019 are provided below.

\begin{tabular}{|c|c|c|c|c|}
\hline Density & Yield strength & Ultimate strength & Modulus of elasticity & Poisson's ratio \\
\hline $7800 \frac{\mathrm{kg}}{\mathrm{m}^{3}}$ & $580 \mathrm{MPa}$ & $750 \mathrm{MPa}$ & $2.1 \cdot 10^{11} \mathrm{~Pa}$ & 0.28 \\
\hline
\end{tabular}

Table 2. Material properties - DIN 1.0503 steel

The stress analysis will be performed at 14 different positions of the crankshaft during an engine cycle, with the engine speed of $2800 \mathrm{rpm}$, in order to get the stress history needed for the fatigue analysis. The chosen positions, shown in Fig. 4 , represent loading conditions at which the total or one of the component forces reach their maximum, minimum or zero value. The loading conditions at these positions are provided by the earlier made MATLAB program. 
Radial and tangential components of the total force will be applied only to one half of the rod journal's cylindrical surface and the exact portion of the surface will differ at every position, dependent on the angle of the crankshaft, i.e. they rotate with the crankshaft. Boundary conditions simulating the bearings will be applied similarly, according to recommendations from [2], [8] and [11]. Single cylinder crankshafts are mounted on the engine block with a rolling bearing on one side and a journal bearing on the other. The rolling bearing prevents all motion except the rotation around the longitudinal axis, while the journal bearing also allows sliding in the longitudinal direction. Constraints simulating the rolling bearing will be applied on one half of the main journal cylindrical surface, while the constraints simulating the journal bearing will be applied on a semicircular ring. Surfaces of the rod and main journals are going to be divided with the SolidWorks Split tool, using two planes that will remain parallel to each other in every crankshaft position, ensuring the congruence of the boundary conditions. Before proceeding with a detailed FEA, the goal is to find the optimal mesh and to make sure the proper boundary conditions are applied. For that reason, the manual h convergence method is used. If the finite element model is correctly established, the approximate results of the simulations should come closer to the results of the real physical system, and therefore also converge to a certain value, when the number of finite elements is increased, because in that case, the distortion energy of the mathematical model converges to the distortion energy of the physical system [20]. Convergence of the results is analysed for the position G (Fig. 4), where the maximum total and bending loads occur, at 8 locations that are deemed critical because of the stress concentrations (Fig. 5). The mesh is additionally refined at these locations, using the Apply Mesh Control tool. Satisfactory convergence is achieved after 8 iterations, but to ensure the reliability of the results, a significantly refined mesh was used in the $9^{\text {th }}$ iteration. Since the results stayed on the same level, the stress analysis for the other 13 positions used the mesh from the $8^{\text {th }}$ iteration. Properties of that mesh are provided in Table 3. The maximum stress occurs at the locations 2 and 7 , at the end of the compression stroke (position G). Since the stresses at locations 1 and 5 are significantly lower than the stresses at other locations, they will be omitted in the further analysis.

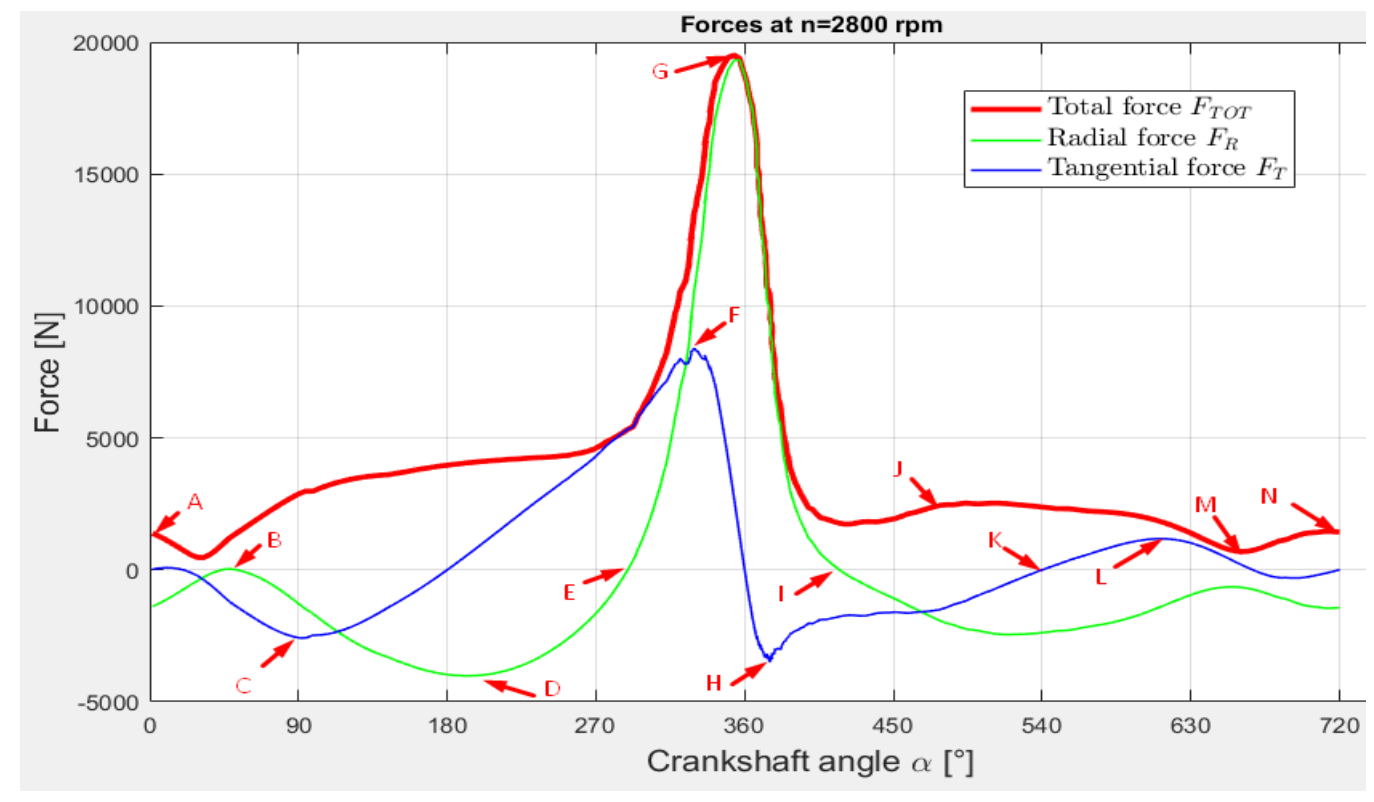

Fig. 4. Chosen positions at $2800 \mathrm{rpm}$

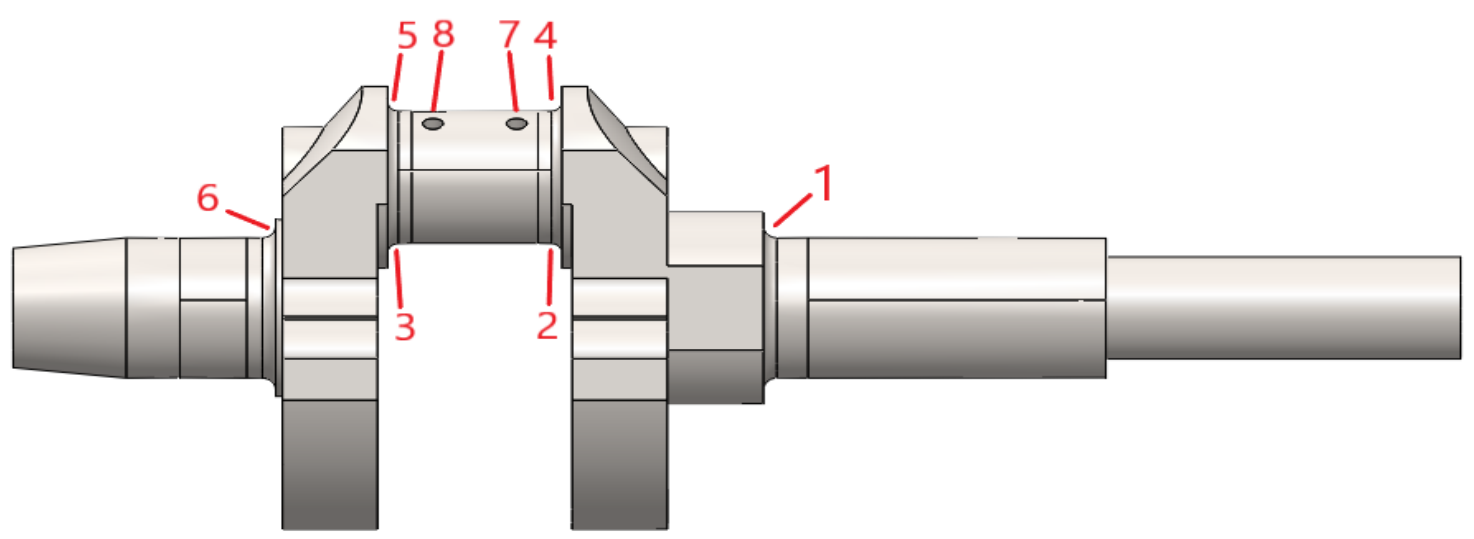

Fig. 5. Chosen locations on the crankshaft 


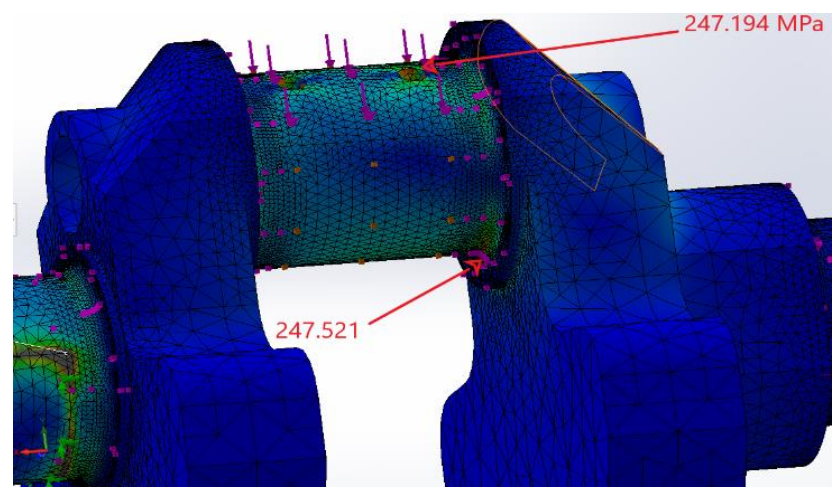

Fig. 6. Maximum stresses during an engine cycle

\begin{tabular}{|c|c|c|c|c|}
\hline No. of elements & No. of nodes & Aspect Ratio (AR) & Elements with AR < 3 & Jacobian Check \\
\hline 257.749 & 378.882 & 7.1073 & $99.6 \%$ & 2.514 \\
\hline
\end{tabular}

Table 3. Properties of the chosen optimal mesh

\section{Fatigue Analysis}

Although the stresses at the chosen locations don't exceed the material's yield strength in any loading condition during the engine cycle ( $247.52 \mathrm{MPa}<580 \mathrm{MPa}$ ), there is still a possibility that the failure could occur due to the fatigue of the material. Failure of a crankshaft caused by fatigue can occur at locations where the stress is 4 times smaller than the material's yield strength [5]. The mean stress $\left(\sigma_{\mathrm{s}}\right)$, alternating stress $\left(\sigma_{\mathrm{a}}\right)$ and stress range are the key stress components that are used to assess the fatigue life of a machine element. Based on the stress history obtained from the stress analysis for the 14 positions of the crankshaft, these components were calculated at the remaining 6 critical locations, as depicted in the Fig. 9. SolidWorks Simulation reports the stress results as Von Mises stress, which is always positive. To determine the actual sign (whether it is tensile or compressive) of the stress at a location, the sign of the principle stress with the largest absolute value at that location was used. Only then can the aforementioned stress components be calculated. From Fig. 7. it is obvious that the highest level of stress is present at the locations 2 and 7. Although the absolute stress component values at these locations are almost identical, only the location 2 will be taken into account in the following fatigue analysis. The reason for this is that the mean stress at this location is positive (tensile) while at location 7 it is negative (compressive). Tensile stresses cause the crack propagation and fatigue failure at a location, while the locations at which the mean stress is negative only have to be evaluated from the standpoint of yield or ultimate strength [21], which has already been done in the stress analysis. Stress components for the only remaining critical location are provided in Table 3.

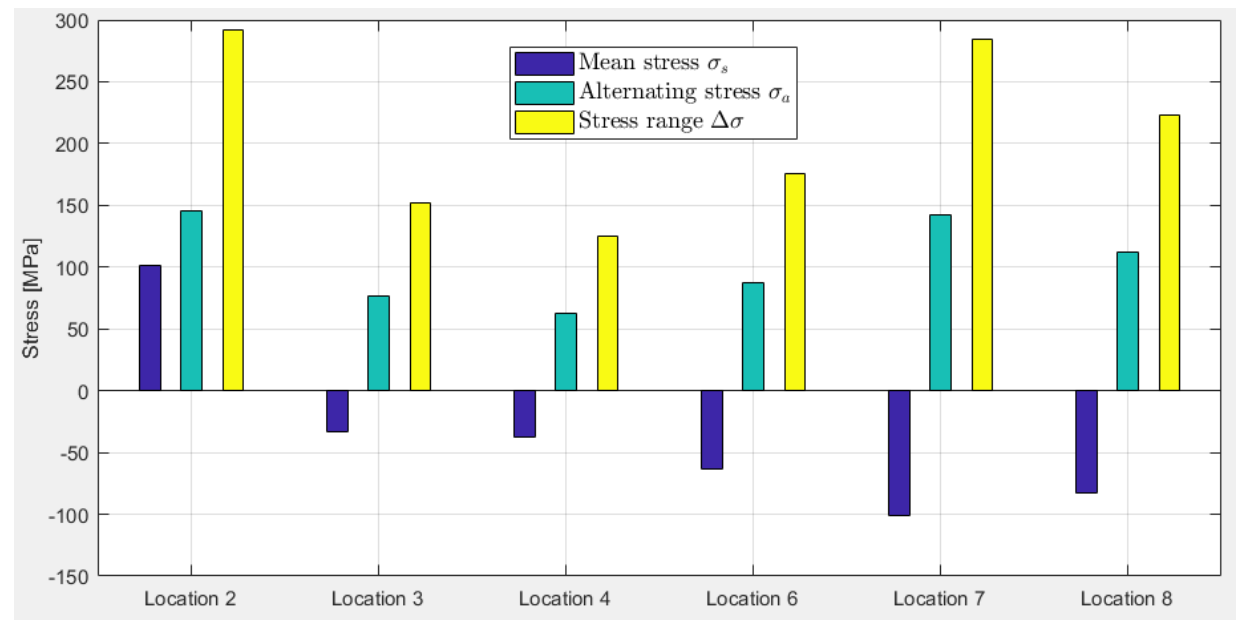

Fig. 7. Stress components at the remaining 6 critical locations

\begin{tabular}{|c|c|c|c|c|}
\hline Max. stress & Min. stress & Mean stress & Alternating stress & Stress range \\
\hline 246.91 & -45.07 & 100.92 & 145.99 & 291.99 \\
\hline
\end{tabular}

Table 4. Stress components for the critical location 2 (in MPa) 
The ratio of the minimum and maximum stress at the critical location of the crankshaft is usually around -0.2 [2]. For the location 2, based on data from Table 3:

$$
\mathrm{r}=\frac{\sigma_{\min }}{\sigma_{\max }}=\frac{-45.073 \mathrm{MPa}}{246.912 \mathrm{MPa}}=-0.1825
$$

Since the integrity of the whole engine depends on the reliability of the crankshaft, it is necessary to design it for infinite life. For steels, the number of cycles to reach the infinite life region is usually between $10^{6}$ and $10^{7}$ [21]. There are two main approaches in analysis of the fatigue life of a component, the stress-life approach (SN) and the strain-life approach $(\varepsilon N)$. The stress-life approach is used for high-cycle fatigue conditions (number of cycles to failure $\mathrm{N}_{\mathrm{f}}>10^{3}$ ), so it will be employed here. Three criterions for calculating the fatigue life that take into account the mean stress are used; the modified Goodman, Gerber and ASME elliptic criterion, given by expressions:

$$
\begin{aligned}
& \frac{S_{a}}{S_{e}}+\frac{S_{m}}{S_{u t}}=1 \\
& \frac{S_{a}}{S_{e}}+\left(\frac{S_{m}}{S_{u t}}\right)^{2}=1 \\
& \left(\frac{S_{a}}{S_{e}}\right)^{2}+\left(\frac{S_{m}}{S_{y}}\right)^{2}=1
\end{aligned}
$$

Since the SN diagrams are only applicable to completely reversed stresses $(r=-1)$, to predict the fatigue life for fluctuating stresses, an equivalent completely reversed stress, as damaging as the fluctuating stress, needs to be obtained [21]. This is achieved by replacing the endurance limit $S_{e}$ from the equations (8), (9) and (10) with the equivalent completely reversed stress $\sigma_{-1}$ :

$$
\begin{gathered}
\sigma_{-1 \_ \text {Goodman }}=\frac{\mathrm{S}_{\mathrm{a}}}{1-\frac{\mathrm{S}_{\mathrm{m}}}{\mathrm{S}_{\mathrm{ut}}}}=168.69 \mathrm{MPa} \\
\sigma_{-1 \_ \text {Gerber }}=\frac{\mathrm{S}_{\mathrm{a}}}{1-\left(\frac{\mathrm{S}_{\mathrm{m}}}{\mathrm{S}_{\mathrm{ut}}}\right)^{2}}=148.68 \mathrm{MPa} \\
\sigma_{-1 \_A S M E}=\frac{\mathrm{S}_{\mathrm{a}}}{\sqrt{1-\left(\frac{\mathrm{S}_{\mathrm{m}}}{\mathrm{S}_{\mathrm{y}}}\right)^{2}}}=148.25 \mathrm{MPa}
\end{gathered}
$$

Now the number of cycles to failure can be found with the expressions $(14,15,16,17)$ provided in [21]. $\sigma_{\mathrm{f}}^{\prime}$ is the fatigue strength coefficient and $\mathrm{b}$ is the fatigue strength exponent, and for the chosen material, they were experimentally found to be $\sigma_{f}^{\prime}=1124 \mathrm{MPa}, b=-0.079$ [3]. After calculating the number of cycles to failure for the chosen criterions, the minimum number of cycles was found to be 254.536 .494 (modified Goodman criterion), which suggests that the crankshaft enters the infinite life region. However, these results must be taken with caution, since many factors that reduce the life of a component haven't been taken into account, such as the temperature loads, surface quality and other working conditions. On the other hand, the treatments that the crankshaft undergoes that increase the fatigue life, like fillet rolling, were also neglected.

$$
\begin{aligned}
& \mathrm{N}_{\mathrm{f}}=\left(\frac{\sigma_{-1}}{\mathrm{a}}\right)^{\frac{1}{\mathrm{c}}} \\
& \mathrm{f}=\frac{\sigma_{\mathrm{f}}^{\prime}}{\mathrm{S}_{\mathrm{ut}}}\left(2 \times 10^{3}\right)^{\mathrm{b}} \\
& \mathrm{a}=\frac{\left(\mathrm{fS}_{\mathrm{ut}}\right)^{2}}{\mathrm{~S}_{\mathrm{e}}} \\
& \mathrm{c}=-\frac{1}{3} \log \left(\frac{\mathrm{fS}_{\mathrm{ut}}}{\mathrm{S}_{\mathrm{e}}}\right)
\end{aligned}
$$


The results from the analytical analysis were compared with those from a numerical analysis in the SolidWorks Simulation Fatigue Analysis module. Since the stress analysis in this study was done only for one engine speed, the Constant amplitude events with defined cycles type of analysis was set. The data for the S-N curve for the $\mathrm{r}=-0.2$ loading condition was imported from [3]. SolidWorks calculates the mean stresses in the same way as it was done in this study (according to the signs of principle stresses) but provides the user with more options for calculating the alternating stress, among which the principle stress sign method was chosen, in order to be compatible with the analytical analysis. Three criterions for taking into account the mean stresses are provided; modified Goodman, Gerber and Soderberg criterion. Analyses with all three criterions were conducted, and none of them reported the number of cycles to failure at the critical location to be in the finite life region, which is in accordance with the findings of the analytical analysis.

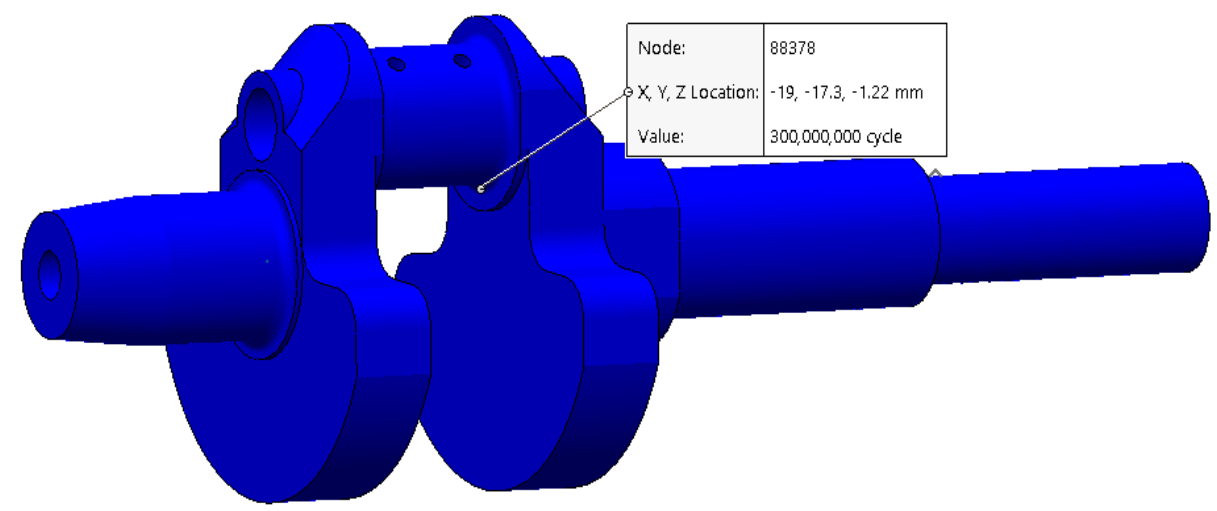

Fig. 8. Fatigue analysis results at the critical location using the Soderberg criterion

\section{Conclusions}

The results of the stress analysis of the crankshaft conducted in this paper are in accordance with the expectations based on the literature review. The critical location is exactly the same as it was found to be in almost every study reviewed, as stated before. Convergence of stress results has been achieved at this location, which further encourages the reliability of the findings. The stress history was used for the analytical fatigue life estimations, which were later compared with those from a numerical analysis in SolidWorks 2019.

Although estimations from both analyses concur, more detailed fatigue analysis is recommended. Based on the conducted analysis, the following recommendations can be provided for improving the reliability of the crankshaft and extending its fatigue life:

- increasing the diameter of the rod journal;

- increasing the radius of the fillet at the critical locations;

- paying special attention to the surface and heat treatment processes at the critical locations, i.e. the filleted regions at the rod journals.

The developed numerical model and the results obtained in this paper can serve as a basis for future researches. Ideally, the development of such an element as the crankshaft should be verified by experimental fatigue tests. After obtaining reliable life estimations, an optimization study of the crankshaft's geometry could be carried away.

\section{References}

[1] Kaufman, J.G \& Rooy, E.L. (2004). Aluminum Alloy Castings: Properties, Processes, and Applications, ASM International, ISBN: 0-87170-803-5, Materials Park, Ohio, USA

[2] Fatemi, A. \& Montazersadgh, F. (2007). Stress Analysis and Optimization of Crankshafts Subject to Dynamic Loading, A Final Project Report Submitted to the Forging Industry Educational Research Foundation (FIERF) and American Iron and Steel Institute (AISI), University of Toledo

[3] Williams, J. \& Fatemi, A. (2007). Fatigue Performance Comparison and Life Predictions of Forged Steel and Ductile Cast Iron Crankshafts, A Final Project Report Submitted to the Forging Industry Educational Research Foundation (FIERF) and American Iron and Steel Institute (AISI), University of Toledo

[4] Balamurugan, C.M.; Krishnaraj, R.; Sakthivel, M; Kanthavel, K; Deepan Marudachalam M.G, Palani, R. (2011). Computer Aided Modeling and Optimization of Crankshaft, International Journal of Scientific \& Engineering Research, Vol. 2, No. 8, (August 2011), ISSN: 2229-5518

[5] Witek, L.; Sikora, M.; Stachowicz, F. \& Trzepiecinski, T. (2011). Stress and Failure, Analysis of the Crankshaft of Diesel Engine, Engineering Failure Analysis, Vol.82, (December 2017) 703-712, ISSN: 1350-6307

[6] Silva, F.S. (2003 a). Analysis of a Vehicle Crankshaft Failure, Engineering Failure Analysis, Vol. 10, Issue 5, (October 2003) 605-616, doi:10.1016/S1350 6307(03)00024-4 
[7] Silva, F.S. (2003 b). An Investigation into the Mechanism of a Crankshaft Failure, Key Engineering Materials, Vols. 245-246, (July 2003) 351-358, doi:10.4028/www.scientific.net/KEM.245-246.351

[8] Montazersadgh, F. \& Fatemi, A. (2007 a). Dynamic Load and Stress Analysis of a Crankshaft, SAE Technical Paper 2007-01-0258, ISSN: 0148-7191, Warrendale, PA, USA

[9] Montazersadgh, F. \& Fatemi, A. (2007 b). Optimization of a Forged Steel Crankshaft Subject to Dynamic Loading, SAE Technical Paper 2008-01-0432, ISSN: 1946-3987, Warrendale, PA, USA

[10] Weis, O. \& Kroft, L. (2019). Improved Performance of Crankshaft for Vehicle Tatra 12, Proceedings of the 30th DAAAM International Symposium, pp.1034-1040, B. Katalinic (Ed.), Published by DAAAM International, ISBN 978-3-902734-22-8, ISSN 1726-9679, Vienna, Austria, DOI: 10.2507/30th.daaam.proceedings.144

[11] Meng, J.; Liu, Y. \& Liu, R. (2011). Finite Element Analysis of a 4-Cylinder Diesel Crankshaft, International Journal of Image, Graphics and Signal Processing, Vol. 3, Issue 5, (August 2011) 22-29, ISSN: 2074-9082

[12] Fan, J.; Li, B. \& Zhang, Y. (2011). Finite Element Analysis of Crankshaft in ABAQUS, Proceedings of the Second International Conference on Digital Manufacturing \& Automation, Werner, B. (Ed.), pp. 545-548, ISBN 978-1-4577-0755-1, Zhangjiajie, China (August 2011), IEEE Computer society, Los Alamitos, USA

[13] Degefe, M.; Paramasivam, P.; Dabasa, T. \& Kumar, V. (2017). Optimization and Finite Element Analysis of Single Cylinder Engine Crankshaft for Improving Fatigue Life, American Journal of Mechanical and Materials Engineering, Vol. 1, No. 3, (September 2017) 58-68, DOI: 10.11648/j.ajmme.20170103.11

[14] Fonte, M.; Duarte, P.; Reis, L.; Freitas, M. \& Infante, V. (2015). Failure Mode Analysis of Two Crankshafts of a Single Cylinder Diesel Engine, Engineering Failure Analysis, Vol. 56, (October 2015) 185-193, doi.org/10.1016/j.engfailanal.2015.02.014

[15] Bayrakceken, F.; Tasgetiren, S.; Aksoy, F. (2007). Failures of Single Cylinder Diesel Crank Shafts, Engineering Failure Analysis, Vol. 14, No. 4, (June 2007) 725- 730, ISSN: 1350-6307

[16] Rohatgi, A. (2020). WebPlotDigitizer, Available from https://automeris.io/WebPlotDigitizer, Accessed: 2020-0821

[17] Yingkui, G. \& Zhibo, Z. (2011). Strength Analysis of Diesel Engine Crankshaft Based on PRO/E and ANSYS, Proceedings of the Third International Conference on Measuring Technology and Mechatronics Automation, Werner, B. (Ed.), pp. 362-364, ISBN 978-1-4244-9010-3, Shanghai, China, (January 2011), IEEE Computer society, Los Alamitos, USA

[18] Bathe, K-J. (2016). Finite Element Procedures, K.J. Bathe, ISBN: 978-0-9790049-5-7, Watertown, USA

[19] Zienkiewicz, O.C.; Taylor, R.L. \& Zhu, J.Z. (2013). The Finite Element Method: Its Basis and Fundamentals, Butterworth-Heinemann, ISBN: 978-1-85617-633-0, Oxford, Great Britain

[20] Sorić, J. (2004). Metoda konačnih elemenata (Finite Element Method), Golden Marketing-Tehnička knjiga, ISBN: 953-212-210-9, Zagreb, Croatia

[21] Budynas, R. \& Nisbett, K. (2011). Shigley's Mechanical Engineering Design, McGraw-Hill, ISBN: 978-0-07352928-8, New York, USA 